\title{
NGHIÊN CƯU LỘI ÍCH CỦA DÂY CHẰNG NHÂN TẠO TRONG SỬA VAN HAI LÁ THOÁI HÓA
}

Nguyê̂n Văn Nghĩa*

\section{TÓM TÁT}

Tiền cứu hàng loạt ca các trường hợp lâm sàng từ năm 2015 đến năm 2018 trên các số liệu thu thập được từ 27 bệnh nhân được phẫu thuật sửa van hai lá sử dụng dây chằng nhân tạo và khám lại sau phẫu thuật.

Kết quả: Sau 2 năm theo dõi, không có trường hợp tử vong, và $96,3 \%$ không cần mổ lại. 96,3\% trường hợp không hở van hai lá tồn lưu hoặc hở nhẹ; phân suất tống máu tăng sau phẫu thuật, trung bình là $58.22 \%$ sau 1 tháng và $61.3 \%$ sau 3 tháng; $49.1 \%$ trường hợp rung nhĩ trước mổ có nhịp xoang trở lại sau 3 tháng đến 1 năm theo dõi, trong đó $14,8 \%$ trường hợp được phẫu thuật Maze kết hợp sửa van; vòng van nhân tạo số 28 chiếm $38.3 \%$, vòng van số 30 chiếm $22.2 \%$, còn lại là vòng van lớn từ $32,34,36$.

Kết luận: Sử dụng dây chằng nhân tạo trong sửa van hai lá thoái biến mang lại những lợi ích lớn cho bệnh nhân. Uuu điểm của phẫu thuật này giúp cải thiện chức năng thất trái, tăng phân suất tống máu, nhịp xoang trở lại ổn định sau phẫu thuật. Nhờ dây chằng nhân tạo, không cắt bỏ mô van, giúp đặt được vòng van nhân tạo kích thước tối đa phù hợp cho bệnh nhân.

Từ khóa: Sửa sa van hai lá, Dây chằng nhân tạo, Bệnh van tim thoái hóa.

\section{SUMMARY}

From 2015 to 2018, 27 patients underwent mitral valve repair by the technique of applying artifitial chordae in the Heart Institute of Ho Chi Minh, Vietnam. Valve disease was degenerative in most cases. No death after 2 years of follow-up overall. Freedom from re-operation at 2 years was $96.3 \%$ ( 1 case of re-operation related to cardiac insufficiency. The grades of mitral regurgitation at 2 years were $96.3 \%$ absent or mild, $3.7 \%$ moderate. ). Good heart function after the repair, EF $58.22 \%$ at 1 month, and $61.3 \%$ at 3 months and stable after that; sinus rhythm by 2-year follow-up ( with 14.8\% Maze procedure applied). Ring used for most of cases after the valve repair, from size of 28 to 36. This study showed strong benefits and excellent results of mitral valve repair by applying artifitial chordae at 2-year follow-up, confirming reliablility and durability of this technique for the patients. This showed a good solution for mitral regurgitation by safe technique, and increase feasibility of mitral valve repair.

Key word: mitral valve repair, artifitial chordae, neo-chord, degenerative disease.

\section{I. ĐặT VẤN ĐỀ}

Bệnh hở van hai lá có nhiều nguyên nhân, trong đó chủ yếu là thấp tim, bẩm sinh và thoái hóa. Đối với trường hợp thoái hóa van, phẫu thuật sửa van được đặt lên hàng đầu.

Trong hơn 30 năm qua, chỉ PTFE (polytetrafluoroethylene) hay chỉ Gore-tex được sử dụng làm dây chằng nhân tạo, sử dụng trong sửa van hai lá đã có nhiều công trình nghiên cứu của nhiều tác giả khác nhau trên thế giới, đã khẳng định sự ưu việt và lợi ích của phương pháp này đối với bệnh nhân hở van hai lá. Tuy nhiên, các công trình nghiên cứu về sửa van hai lá tại Châu Á còn tương đối hạn chế. Tại Việt Nam, phẫu thuật van tim cũng có bề dày phát triển đáng kể. Mặc dù vậy, những nghiên cứu về sửa van hai lá sử dụng dây chằng nhân tạo chưa được thực hiện nhiều. Chính vì điều này, chúng tôi đã tiến hành nghiên cứu trên nhóm bệnh nhân Việt Nam

* Khoa phẫu thuật - Viện Tim TP.HCM Nguoòi chịu trách nhiệm khoa học: Nguyễn Văn Nghĩa Ngày nhận bài: 02/08/2020 - Ngày Cho Phép Đăng: 04/09/2020

Phản Biện Khoa học: PGS.TS. Đạng Ngọc Hùng PGS.TS. Đoàn Quốc Hưng 
tại Viện Tim TP. Hồ Chí Minh nhằm xác định lợi ích của phương pháp này trong điều trị ngoại khoa bệnh hở van hai lá ở Việt Nam.

\section{Mục tiêu nghiên cứu}

- Đánh giá lợi ích của việc bảo tồn mô van khi sử dụng dây chằng nhân tạo trong phẫu thuật sửa sa van hai lá.

- Xác định tỉ lệ hở van hai lá tồn lưu và các biến chứng sau phẫu thuật

\section{II. ĐỐI TƯợNG - PHƯƠNG PHÁP NGHIÊN CÚU}

\section{1. Đối tượng nghiên cứu:}

\subsubsection{Dân số nghiên cứu:}

Tất cả bệnh nhân được phẫu thuật sửa sa van hai lá sử dụng dây chằng nhân tạo tại Viện Tim Tp.HCM trong thời gian từ năm 2015 đến 2018.

\subsubsection{Tiêu chuẩn chọn bệnh}

Tất cả bệnh nhân được phẫu thuật sửa van hai lá sử dụng dây chằng nhân tạo trong thời gian từ năm 2015 đến 2018.

\subsubsection{Tiêu chuẩn loại trù̀}

Bệnh nhân hở van hai lá được thay van nhân tạo.

Bệnh nhân sửa van hai lá nhưng dùng các phương pháp khác với dây chằng nhân tạo.

Bệnh nhân hở van hai lá trong bệnh lý nhiều van phối hợp.

\subsection{Phương pháp nghiên cứu:}

2.2.1. Thiết kế nghiên cúu: Tiền cứu hàng loạt ca.

\subsubsection{Thu thập số liệu}

Dựa vào bệnh án mẫu, số liệu được thu thập tại Viện Tim thành phố Hồ Chí Minh.

\subsubsection{Phân tích và xủ lý số liệu}

Số liệu được xử lý bằng phương pháp thống kê, có hỗ trợ bằng phần mềm SPSS 16.0. Phân tích tổng hợp các dữ kiện lâm sàng, các phương pháp mổ, kết quả phẫu thuật, các biến chứng sau khi mổ.

\subsubsection{Phương pháp tiến hành:}

Xác định chiều dài dây chằng nhân tạo và kỹ thuật đặt dây chằng. Nghiên cứu này áp dụng phương pháp đặt dây chằng nhân tạo của tác giả Nguyễn Văn Phan:

Bước 1: Xác định vị trí sa van hai lá

Bước 2: Chọn vị trí van bình thường (kế bên vùng sa van), gắn chỉ 5.0 qua lá trước và lá sau

Bước 3: Khâu chỉ PTFE từ cơ nhú lên vùng lá van bị sa.

Bước 4: Chỉ 5.0 căng lên để làm chiều dài chuẩn.

Bước 5: Cột chỉ PTFE ngang mức chiều dài chuẩn

Bước 6: Cột chỉ một lần nữa ở mặt dưới lá van

Bước 7: Bơm nước muối sinh lý vào Thất trái để kiểm tra

\subsubsection{Theo dõi ngắn hạn:}

* Sau mổ từ 1 đến 7 ngày, theo dõi các biến chứng phẫu thuật: Chảy máu, đau sau mổ, siêu âm tim.

* Từ 7 ngày sau mổ - 3 tháng sau mổ: siêu âm tim kiểm tra độ hở van 2 lá tồn lưu.

2.2.6. Theo dõi trung hạn: Siêu âm tim kiểm tra sau mổ 6 tháng -1 năm

\section{KẾT QUẢ}

\section{1. Đặc điểm đối tượng nghiên cứu}

Nam giới chiếm tỷ lệ cao hơn nữ giới $(63 \%$ so với 37\%). Tuổi trung bình là 51.67 (tuổi), lớn nhất là 77 tuổi, thấp nhất là 30 tuổi. 
Bảng 1. Phân bố vùng lá van sử dụng dây chằng: Đây là vị trí vùng van được sử dụng dây chằng nhân tạo ePTFE.

\begin{tabular}{|c|c|c|}
\hline Dây chằng & Tần số & Tỷ lệ (\%) \\
\hline $\mathrm{A} 1$ & 1 & 3.7 \\
\hline $\mathrm{A} 2$ & 17 & 63.0 \\
\hline $\mathrm{A} 3$ & 1 & 3.7 \\
\hline $\mathrm{P} 1$ & 1 & 3.7 \\
\hline $\mathrm{P} 2$ & 6 & 22.2 \\
\hline $\mathrm{P} 3$ & 1 & 3.7 \\
\hline
\end{tabular}

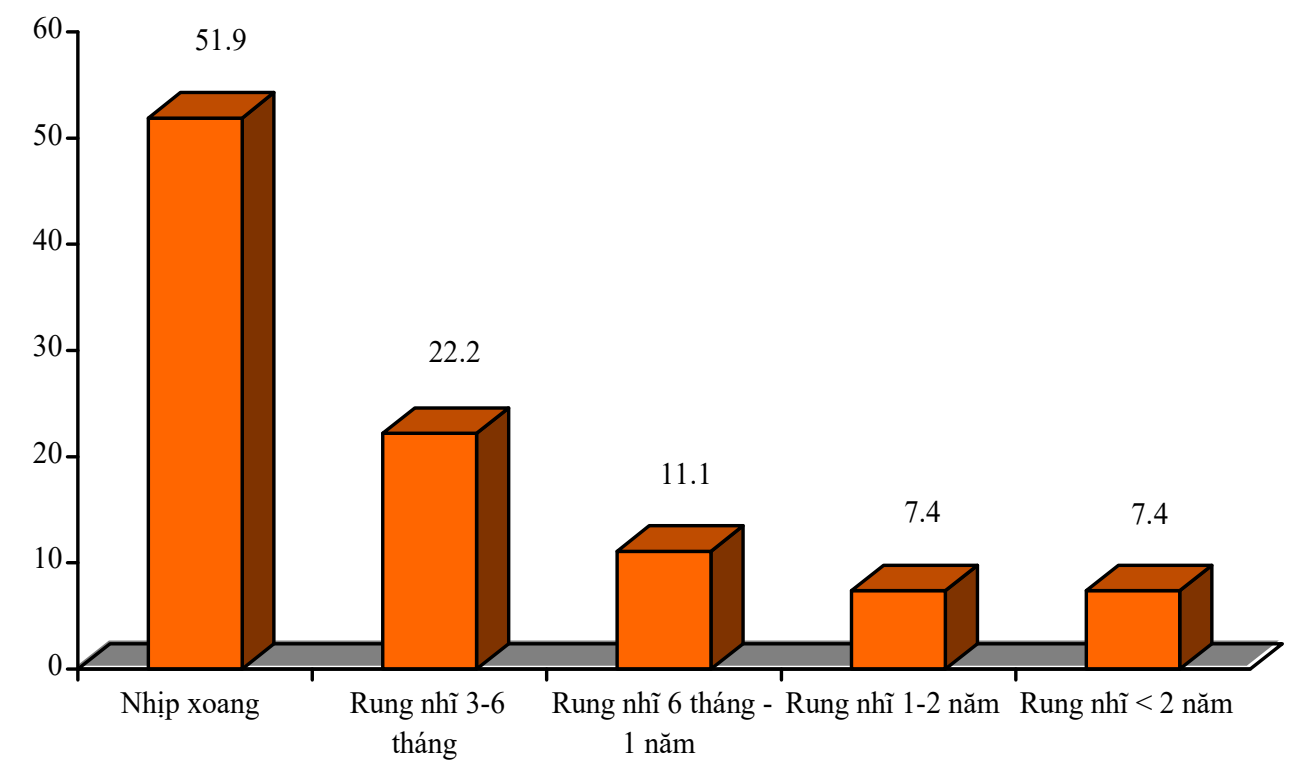

Biểu đồ 1: Tỉ lệ rung nhĩ trước mổ

Bảng 2. Theo dõi rung nhĩ sau mổ

\begin{tabular}{|l|c|c|}
\hline Rung nhĩ & Tần số & Tỷ lệ (\%) \\
\hline Còn & 12 & 44.4 \\
\hline Không & 15 & 55.6 \\
\hline Tổng & 27 & 100 \\
\hline
\end{tabular}

Bảng 3. Hở van 2 lá tồn lưu theo dõi sau mổ

\begin{tabular}{|l|c|c|}
\hline Tồn lưu & Tần số & Tỷ lệ (\%) \\
\hline Hở nhẹ & 6 & 22.2 \\
\hline Không & 21 & 77.8 \\
\hline Tổng & 27 & 100 \\
\hline
\end{tabular}


Bảng 4. Biến chứng sớm

\begin{tabular}{|l|c|c|}
\hline Biến chứng & Tần số & Tỷ lệ (\%) \\
\hline Nhiễm trùng & 1 & 3.7 \\
\hline Chảy máu & 2 & 7.4 \\
\hline Rối loạn nhịp & 2 & 7.4 \\
\hline Tổng & 27 & 100 \\
\hline
\end{tabular}

Bảng 5. Kích thước vòng van nhân tạo sử dụng

\begin{tabular}{|c|c|c|}
\hline Vòng van nhân tạo & Tần số & Tỷ lệ (\%) \\
\hline 28 & 9 & 33.3 \\
\hline 30 & 6 & 22.2 \\
\hline 32 & 4 & 14.8 \\
\hline 34 & 4 & 14.8 \\
\hline 36 & 4 & 14.8 \\
\hline Tổng & 27 & 100 \\
\hline
\end{tabular}

\subsection{Theo dõi sau mổ:}

Kết quả siêu âm tim kiểm tra sau phẫu thuật ghi nhận 6 trường hợp hở van hai lá tồn lưu mức độ nhẹ, không có tắc nghẽn đường ra thất trái ( SAM ), kể cả theo dõi ở những lần bệnh nhân tái khám. Không thuyên tắc do huyết khối hoặc viêm nội tâm mạc nhiễm trùng.

Ngoài ra, ghi nhận tràn dịch màng tim chiếm 2/27 trường hợp, được dẫn lưu. Tất cả bệnh nhân tái khám đều. Không có trường hợp tử vong sau phẫu thuật.

\section{BÀN LUẬN}

4.1. Dây chằng nhân tạo giúp bảo tồn mô van mang tính hiệu quả cao. Xử trí được những thương tổn phức tạp, nhiều thành phần.

Chỉ ePTFE được gắn vào lá van để thay thế cho các dây chằng bị hư.

Dây chằng nhân tạo được gắn vào phần lá trước chiếm $70.4 \%$, riêng $\mathrm{A} 2$ chiếm nhiều nhất $63 \%$; phần lá sau chiếm $29.6 \%$, trong đó, P2 chiếm $22.2 \%$. Đây là những tổn thương diện rộng trên van hai lá, nếu áp dụng những kỹ thuật cổ điển để sửa van sẽ làm mất nhiều mô van, ảnh hưởng lớn đến hình thái và chức năng của tim sau phẫu thuật. Ngoài ra, những kỹ thuật cổ điển trên không dễ để thực hiện, cần có phẫu thuật viên có nhiều kinh nghiệm trong sửa van hai lá. Tuy nhiên, kỹ thuật sửa van với dây chằng nhân tạo có thể thay thế được những kỹ thuật trên, và sửa chữa hiệu quả với sa van hai lá diện rộng.[2]

\subsection{Dây chằng nhân tạo mang tính linh hoạt}

Dây chằng nhân tạo mang tính linh hoạt bởi: số lượng dây chằng tạo và chiều dài dây chằng nhân tạo có thể thay đổi tùy thuộc vào thương tổn khác nhau. Trong nghiên cứu, chúng tôi sử dụng dây chằng nhân tạo bằng chỉ Polytetraflouroethylene 3-0, 4-0 hoặc 5-0, có độ linh hoạt, độ bền cao đã được chứng thực qua nhiều nghiên cứu của các tác giả Braunberger $\mathrm{E}$, Chauvaud S [4].

Nghiên cứu của tác giả Toshiko Shibata sửa van hai lá dùng dây chằng nhân tạo đa vòng qua đường mở giữa xương ức trên 180 bệnh nhân có kết quả: số vòng lặp trung bình sử dụng cho lá trước là 2 vòng lặp, lá sau là 2 vòng lặp và cả hai 
lá trước sau là 3 vòng lặp; Chiều dài dây chằng trung bình ở lá trước là $18 \mathrm{~mm}$, lá sau là $17 \mathrm{~mm}$, cả hai lá là $18 \mathrm{~mm}[10]$.

Một nghiên cứu khác của tác giả Hiroki Hata nghiên cứu trên 224 bệnh nhân sử dụng dây chằng nhân tạo đơn sợi sửa van hai lá. Kết quả số dây chằng sử dụng trung bình là 3.7 dây chằng/bệnh nhân, trường hợp nhỏ nhất là 2 dây chằng và nhiều nhất là 12 dây chằng.[6]

Trong nghiên cứu của chúng tôi ghi nhận, chiều dài cho dây chằng nhân tạo lá sau thường từ $16-18 \mathrm{~mm}$, và chiều dài cho dây chằng lá trước thường từ 20-22mm.

\section{3. Đặt vòng van hai lá}

Trong nghiên cứu của chúng tôi, tất cả các trường hợp đều được đặt vòng van nhân tạo sau khi sửa van hai lá. Các kích thước vòng van được sử dụng từ 28 đến 36 , trong đó nhiều nhất là 28 , chiếm 33.3\%. Trong nghiên cứu 224 trường hợp của tác giả Hiroki Hata, $81.7 \%$ bệnh nhân được đặt vòng van nhân tạo. Toshihiko Shibata nghiên cứu 180 trường hợp, 100\% đặt vòng van nhân tạo.[10]

\subsection{Biến chứng và hở van hai lá tồn lưu}

Theo báo cáo của trung tâm phẫu thuật Mayo Cinic và báo cáo của hiệp hội phẫu thuật lồng ngực (STS năm 2009), tỉ lệ tử vong tại viện sau phẫu thuật sửa van hai lá từ $1-2.6 \%$ [7]. Những biến chứng có thể xảy ra sau phẫu thuật: hở van hai lá tồn lưu ngay sau phẫu thuật 3-4.5\% [8]; tắc nghẽn đường ra thất trái từ 5-10\% [8]; thuyên tắc do huyết khối và viêm nội tâm mạc hiễm trùng rất hiếm. $85-95 \%$ không phải phẫu thuật lại van hai lá sau 10 năm, 20 năm [5].

\begin{tabular}{|c|c|c|c|c|c|}
\hline \multirow[b]{2}{*}{ Nghiên cứu } & \multicolumn{3}{|c|}{ Biến chứng } & \multirow{2}{*}{$\begin{array}{l}\text { Dẫn } \\
\text { lưu }\end{array}$} & \multirow[b]{2}{*}{ Tử vong } \\
\hline & $\begin{array}{l}\text { Tràn dịch } \\
\text { màng tim }\end{array}$ & $\begin{array}{l}\text { Tràn dịch } \\
\text { màng phổi }\end{array}$ & $\begin{array}{c}\text { Rối loạn } \\
\text { nhịp nặng }\end{array}$ & & \\
\hline Nguyễn Văn Phan (2014) & $22.22 \%$ & $7.41 \%$ & $12.96 \%$ & $3.72 \%$ & $1.75 \%$ \\
\hline Tirone E. David (2013) ${ }^{[5]}$ & & & & & $0.85 \%$ \\
\hline Chúng tôi & $3.7 \%$ & $3.7 \%$ & $7.4 \%$ & $3.7 \%$ & $0 \%$ \\
\hline
\end{tabular}

Trong nghiên cứu của chúng tôi, biến chứng sớm sau phẫu thuật: tràn dịch màng tim là $3.7 \%$; rối loạn nhịp nặng là 7.4\%. Tỉ lệ tràn dịch màng tim trong nghiên cứu của chúng tôi cao hơn của tác giả Nguyễn văn Phan do thời gian khảo sát chúng tôi ngắn. Không có tỉ lệ tử vong sau phẫu thuật. Suy tim mất bù, chức năng co bóp cơ tim thấp dưới $40 \%$, suy đa tạng sau phẫu thuật là những nguyên nhân làm cho tỉ lệ tử vong của các nghiên cứu khác cao hơn chúng tôi.

\section{KẾT LUẬN}

Trong thời gian từ 2015 đến 2018, các trường hợp bệnh nhân hở van hai lá do thoái hóa được phẫu thuật sửa van hai lá có sử dụng dây chằng nhân tạo. Qua quá trình điều trị và theo dõi bệnh nhân, chúng tôi rút ra một số kết luận như sau:
Những lợi ích của phẫu thuật gắn dây chằng nhân tạo trong sửa van hai lá thoái hóa mang lại cho bệnh nhân một phương thức điều trị an toàn và hiệu quả mà không cần cắt bỏ mô van hai lá. Qua theo dõi sau phẫu thuật, gần như van hai lá hoàn toàn không hở hoặc hở nhẹ, kích thước buồng tim nhỏ lại (đường kính cuối tâm trương và tâm thu thất trái giảm có ý nghĩa). Không có tử vong sớm và muộn qua theo dõi, thời gian thở máy và thời gian hồi sức ngắn.

Dây chằng nhân tạo được ứng dụng trong phẫu thuật sửa van hai lá mang lại tính hiệu quả, linh hoạt, tiện lợi và dễ sử dụng.

\section{KIẾN NGH!}

Phẫu thuật sửa sa van hai lá sử dụng dây chằng nhân tạo cần được nghiên cứu theo dõi lâu 
dài hơn để đánh giá đầy đủ về bệnh lý này, và có những kết luận về lâu dài.

Ngoài siêu âm tim qua thành ngực, siêu âm tim qua thực quản [1] giúp đánh giá trước và sau phẫu thuật rất quan trọng trong phẫu thuật cho tất cả các trường hợp sửa van hai lá để đánh giá chính xác thương tổn van hai lá.[1]

\section{TÀI LIỆU THAM KHẢO}

1. Phạm Nguyễn Vinh (2008), "Hở van hai lá". Siêu Âm Tim và Bệnh Lý Tim Mạch, Nhà Xuất Bản Y Học, Thành Phố Hồ Chí Minh, pp. 63-84.

2. Ngô Chí Hiếu, Đỗ Doãn Lợi (2013), "Nghiên cứu sự thay đổi huyết động, hình thái chức năng thất trái sau phẫu thuật sa van hai lá tại bệnh viện Tim Hà nội". Tạp Chí Y Học Thục Hành, 4, pp. 29-33.

3. Nguyễn Văn Phan (2014), "Kết quả phẫu thuật sửa van hai lá trong bệnh Barlow tại viện tim TP.HCM từ 1994 đến 2012". Tạp chi Phẫu thuật tim mạch và lồng ngục Việt Nam, 6, pp. 17-23.

4. Chauvaud S et al (2001), "Long-term (29 years) results of reconstructive surgery in rheumatic mitral valve insufficiency". Circulation, 104 (12 Suppl 1), pp. I12-5.

5. David T. E et al (2013), "Chordal replacement with polytetrafluoroethylene sutures for mitral valve repair: a 25-year experience". $J$ Thorac Cardiovasc Surg, 145 (6), pp. 1563-9.

6. Hata H, Fujita T et al (2015), "A 25-year study of chordal replacement with expanded polytetrafluoroethylene in mitral valve repairdagger". Interact Cardiovasc Thorac Surg, 20 (4), pp. 463-8; discussion 468.

7. Kitahara H, Murata M (2016), "Preservation of Mobility of the Posterior Mitral Leaflet After Mitral Valve Repair With Neochordae Using Loop Technique". Circ J, 80 (3), pp. 663-7.

8. Morris J. D, Penner D. A, Brandt R. L (1964), "Surgical Correction of Ruptured Chordae Tendineae". J Thorac Cardiovasc Surg, 48, pp. 772-80.

9. Ragnarsson S, Sjogren J (2014), "Polytetrafluoroethylene neochordae is noninferior to leaflet resection in repair of isolated posterior mitral leaflet prolapse: a multicentre study". Interact Cardiovasc Thorac Surg, 19 (4), pp. 577-83.

10. Shibata T, Kato Y (2015), "Mitral valve repair with loop technique via median sternotomy in 180 patients". Eur J Cardiothorac Surg, 47 (3), pp. 491-6. 